\title{
High Gain SIW H-Plane Horn Antenna with 3D Printed Parasitic E-Plane Horn
}

\author{
Sheng Huang $\mathbb{D}^{\mathrm{D}}$, King Yuk Chan *, Yu Wang and Rodica Ramer \\ School of Electrical Engineering and Telecommunications, University of New South Wales, \\ Sydney, NSW 2052, Australia; sheng.huang@unsw.edu.au (S.H.); illywang0907@outlook.com (Y.W.); \\ ror@unsw.edu.au (R.R.) \\ * Correspondence: kyc@unsw.edu.au
}

Citation: Huang, S.; Chan, K.Y.; Wang, Y.; Ramer, R. High Gain SIW H-Plane Horn Antenna with 3D Printed Parasitic E-Plane Horn. Electronics 2021, 10, 2391. https:// doi.org/10.3390/electronics10192391

Academic Editor: Athanasios Kanatas

Received: 2 September 2021

Accepted: 25 September 2021

Published: 30 September 2021

Publisher's Note: MDPI stays neutral with regard to jurisdictional claims in published maps and institutional affiliations.

Copyright: (c) 2021 by the authors. Licensee MDPI, Basel, Switzerland. This article is an open access article distributed under the terms and conditions of the Creative Commons Attribution (CC BY) license (https:// creativecommons.org/licenses/by/ $4.0 /)$.

\begin{abstract}
Substrate integrated waveguide (SIW) technology that combines 3D and 2D structures has been successfully utilized due to its notable advantages, including in its application to H-plane horn antennas. As this type of antenna is commonly constructed on thin substrates, the E-plane radiation pattern is always wide, thereby limiting the achievable gain performance. In this work, we propose an approach that incorporates 3D printed horns on a prefabricated SIW H-plane horn antenna to successfully narrow the E-plane radiation pattern, thereby improving the gain performance. The proposed E-plane horn is designed at the aperture of the original H-plane horn, providing a smooth and continuous wave transition from the thin substrate to the end-fire direction. This approach improves the directional radiation performance significantly and reduces fabrication time and associated difficulties as the parasitic structures are simply attached to the SIW horn, without the requirement of redesigning or refabricating the original antenna. From 20 to $25 \mathrm{GHz}$, an optimized prototype shows excellent performance. At $22.7 \mathrm{GHz}$, it exhibits $35^{\circ}$ and $33^{\circ}$ for the $\mathrm{E}$ - and $\mathrm{H}$-plane half-power beamwidths (HPBWs), with corresponding side-lobe levels (SLLs) of $-23 \mathrm{~dB}$ and $-15 \mathrm{~dB}$. The present research reveals that the proposed design presents high feasibility and a reduced demand for high-precision manufacturing processes at a lower cost, concomitantly providing an effective means to further improve on the radiation characteristics.
\end{abstract}

Keywords: substrate integrated waveguide; 3D print; H-plane horn antenna; gain improvement

\section{Introduction}

Substrate integrated waveguide (SIW) technology has attracted a significant level of attention due to its easy integration with planar circuit components, and a low-cost fabrication process [1]. In recent years, the application of microwave devices has become well developed [2-5]. Various antennas with an improved performance have been proposed and designed through the use of SIW technology to meet the different needs of largecapacity transmission [6-9]. Several SIW designs [7-10] have been accomplished with increased radiation and matching performance levels, specifically for directional antennas.

In terms of the gain improvement through radiation characteristics for the SIW Hplane horn antenna, various techniques have been developed aiming for a high directivity [10-16]. A simple approach of extending the dielectric loading to narrow the beam is proposed in [10], and further developed in [11] by reshaping the aperture through the printing metal. In [12], the tapered slots along the electric polarization are designed to narrow the E-plane pattern. Perhaps one major drawback is the bulky antenna size provided by multiple stacked printed circuit boards (PCBs) to ensure the wave propagation. More recently, a SIW H-plane horn antenna combined with a dipole array was proposed in [13], showing an improved radiation performance, including a $14 \mathrm{dBi}$ gain and HPBWs of $44^{\circ}$ and $32^{\circ}$ in E- and H-planes at $20.5 \mathrm{GHz}$. However, this prototype fails to resolve the conflict between the antenna performance and the manufacturing feasibility when considering the fabrication difficulty. 
Recently, the remarkable success of newly emerged 3D printing technology offered an effective platform for increased geometrical and material versatility [17]. Notable 3D printed antenna design examples have been implemented [18-20], showing that both a high radiation performance and a low fabrication cost can be simultaneously fulfilled. A 3D printed metallic Cassegrain antenna with a concave reflector [18] is presented for operation in the Ka-band. The measurements confirm a bandwidth of more than $40 \%$ and a gain of up to $23 \mathrm{dBi}$ for five of the radiating elements. Another 3D printed polarizer, consisting of air and dielectric slabs to enhance the gain by increasing the directivity, is demonstrated in [20]. This antenna design achieves a $50 \%$ impedance bandwidth from 45 to $75 \mathrm{GHz}$, with a gain of up to $15 \mathrm{dBi}$. Based on these examples, 3D printing utilization has spurred our interest in the fabrication of such a design.

In general, for the SIW horn antennas fabricated on thin substrates, the improvement of gain is typically confined to the H-plane because of the inherent SIW structure, while only a few studies have been carried out for the improvement in E-plane performance with a complex design and high cost. To address these issues, we propose an innovative approach to further improve the radiation performance by narrowing the E-plane pattern. This is achieved by introducing two parasitic sets of E-plane horns to a pre-existing SIW H-plane horn antenna [11]. The horns are fabricated by multi-material fused deposition modeling (FDM) with a conductive nano copper wire (NCW) composite.

\section{Antenna Design}

The proposed antenna, with 3D printed E-plane horns, is shown in Figure 1. The 3D printed horns (red parts) are attached symmetrically at the two main radiation sources, the antenna aperture, and the end with the dielectric loading, along the propagation direction. A supporting structure (white part) is printed concomitantly using polylactic acid (PLA), following the same shape of the horn. The geometrical parameters and the dimensions are illustrated in Figure 2 and Table 1.

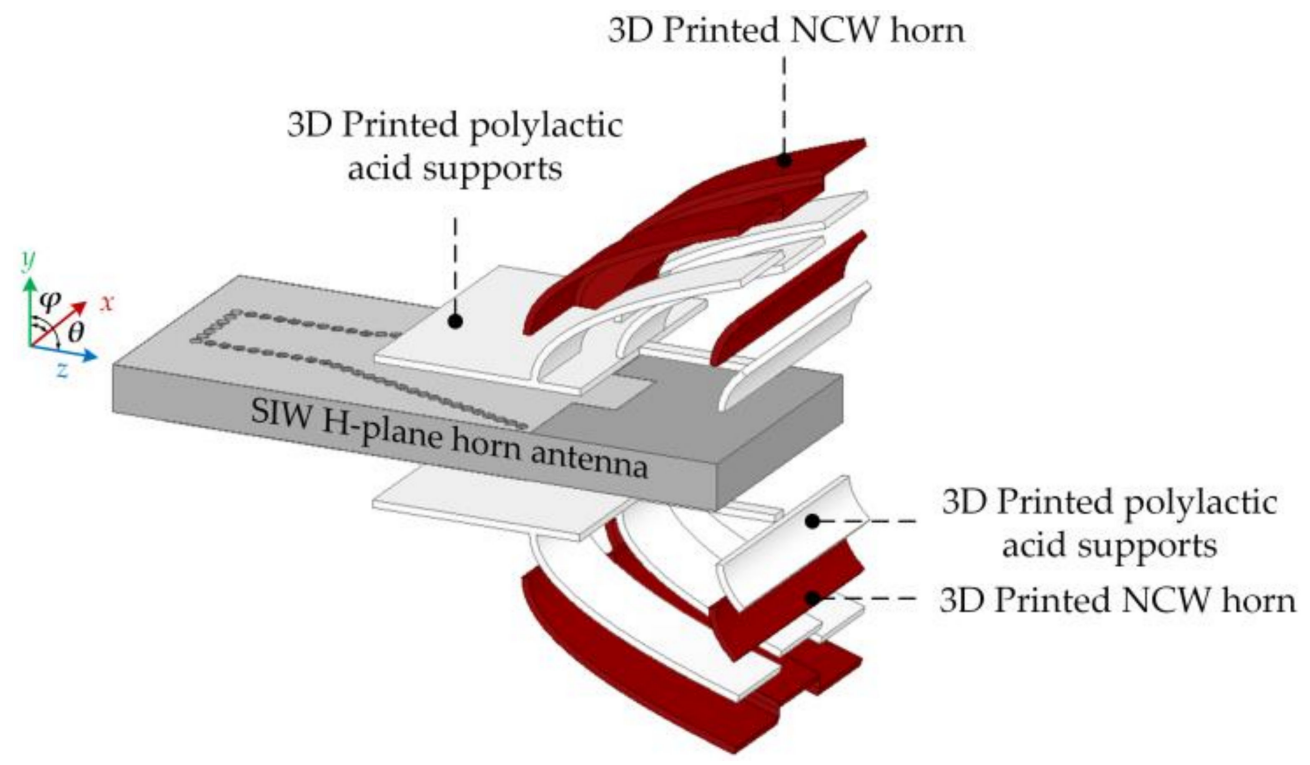

Figure 1. The proposed antenna where the 3D printed NCW horns and their dielectric supports two sides of the SIW antenna. 


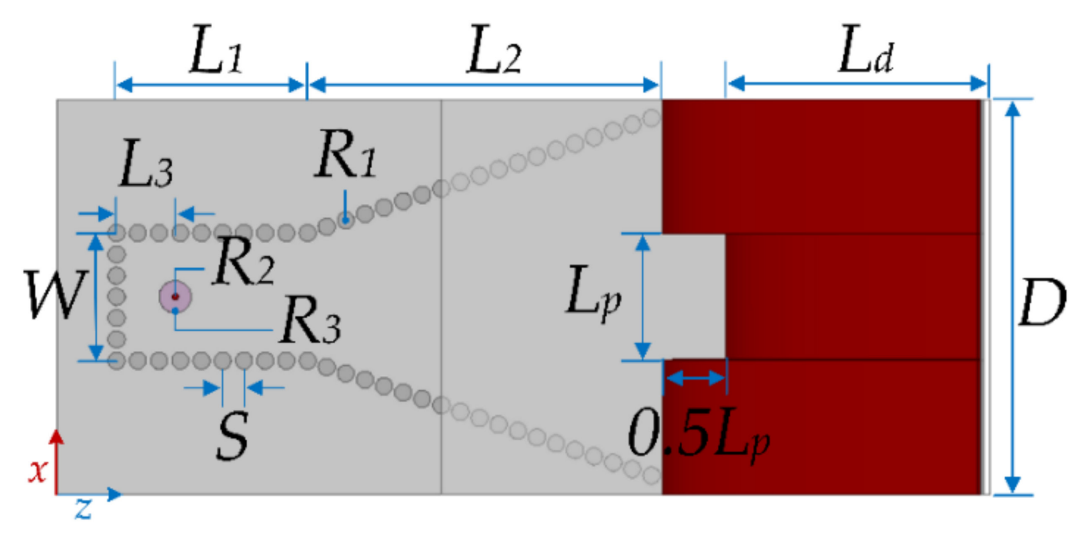

(a)

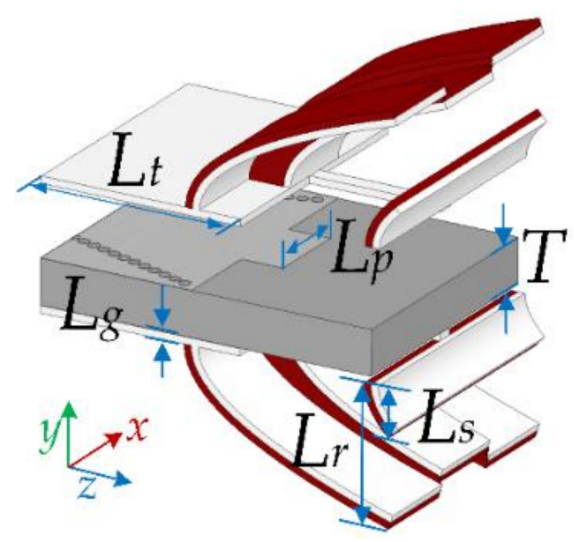

(b)

Figure 2. The proposed SIW horn antenna geometry with labeled parameters. (a) Top view; (b) perspective view of the parasitic E-plane horn.

Table 1. Dimensions of the proposed antenna (values are in millimeters).

\begin{tabular}{ccccc}
\hline Antenna Part & Symbol & Value & Symbol & Value \\
\hline \multirow{3}{*}{ SIW H-plane horn } & $L_{1}$ & 9 & $R_{1}$ & 0.4 \\
& $L_{2}$ & 17.2 & $W$ & 6 \\
& $L_{3}$ & 2.76 & $S$ & 1 \\
\hline \multirow{3}{*}{ Dielectric loading and feeding } & $L_{d}$ & 10 & $R_{2}$ & 0.15 \\
& $L_{p}$ & 6 & $R_{3}$ & 0.76 \\
& $T$ & 3.15 & & \\
\hline \multirow{3}{*}{ Printed parasitic horn } & $L_{r}$ & 9 & $L g$ & 0.5 \\
& $L_{s}$ & 3 & $D$ & 18.6 \\
\hline
\end{tabular}

The SIW antenna is designed using a single layer of Taconic RF45, with a dielectric constant of $\varepsilon_{r}=5.1$ and a thickness of $T=3.15 \mathrm{~mm}$. The radius $R_{1}$ of the metal vias and the distance $S$ between them are calculated based on Equations (1) and (2), and the design rules outlined in $[21,22]$, thereby ensuring minimum leakage. It should be noted that due to the gap between the inserted metal vias in the substrate, traditional SIW technology is suitable for designing the antenna with the given TE mode. The width and length of the SIW feeding are labeled $W$ and $L_{1}$, where the coaxial feed is located a length $L_{3}$ away from the SIW back wall. The radii of the transition pin and the outer conductor are $R_{2}$ and $R_{3}$. The rectangular patches $\left(0.5 L_{p}\right.$ by $\left.L_{p}\right)$, which represent the extension of the top and the bottom metal cladding, lie on the dielectric loading of length $L_{d}$. In terms of the printed structures, the width of the horn and their supporting structures hold the same width $D$ as the antenna aperture and the same dielectric loading. The optimized vertical openings of the horns are labeled $L_{r}$ and $L_{s}$, respectively. The thickness of the dielectric supports is $L_{g}$, and the length is $L_{t}$.

$$
\begin{gathered}
S / R_{1}<2.0 \\
2 R_{1} / W<0.2
\end{gathered}
$$

Our design idea is inspired by the work in [14], where an elliptical SIW H-plane horn, fed by a $90^{\circ}$ coaxial waveguide, is proposed to minimize the length of the traditional H-plane horn. In our case, as the aim is to improve the directivity of the SIW H-plane horn antenna by narrowing the E-plane radiation pattern [23], the surface of the horn is set parallel to the $x$-axis. This is because when the H-plane horn is excited by the SIW fundamental mode $\mathrm{TE}_{10}$, the antenna aperture can be treated as a magnetic current source [24]. Thus, when using a thin substrate, the antenna aperture is closer to an ideal line source for the thickness of the substrates, which is much smaller than the wavelength. 
In terms of the horn shape, our E-plane horns at the antenna aperture and at the end of the dielectric extension in the yoz plane follow the parabola function shown in Equation (3), where $f$ is the focal length and optimized to $1.4 \mathrm{~mm}$. The proposed E-plane horns provide the following advantages: (i) a smooth transition for the electric field radiating from the antenna aperture, contributing to narrowing the E-plane pattern; (ii) they reduce the backward radiation located around the three-quarter wavelength for the radiation at the end of dielectric loading.

$$
z(y)=1 / 4 f y^{2}
$$

\section{The Improvements by the 3D Printed Horns}

\subsection{Comparative Field Analysis}

In this section, we confirm the benefits of the 3D printed E-plane horns by comparing the simulated E-plane field of three investigated antennas, the original antenna without the 3D printed parasitic horns, and the original antennas with parabola and flat horns in the same opening. The simulation is conducted at the designed frequency of $22.7 \mathrm{GHz}$.

The field distributions in the E-plane, at the same frequency, are shown in Figure 3a-c. It is evident that the field distribution of the original antenna is close to the omnidirectional propagation because the electric field at the aperture is compressed more than the wavelength, which results in a wide E-plane beamwidth, as shown in Figure 4a. On the other hand, compared with the flat horn, the wave at the horn aperture of the parabola case is closer to the plane wave, contributing to a narrower E-plane HPBW of around $34^{\circ}$. This is because the parabola horn provides a longer path and smoother transition for the wave near the horn's edge, thereby compensating for the phase difference. Judging from the H-plane patterns in Figure $4 \mathrm{~b}$, the parabola horn can also maintain the narrow HPBW at $27^{\circ}$ because there is no phase-shift modification in this plane.

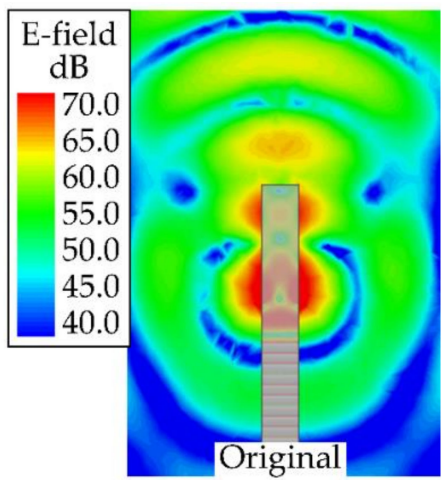

(a)

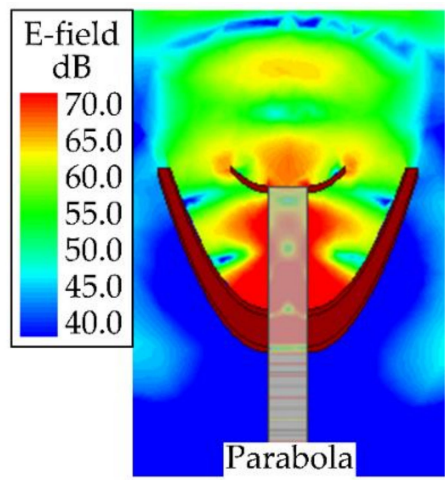

(b)

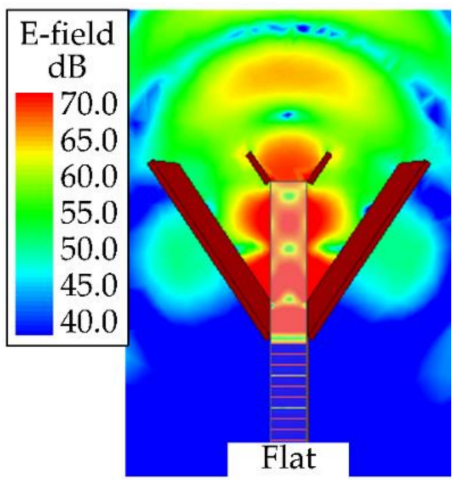

(c)

Figure 3. Simulated E-plane field distributions and radiation patterns of three investigated antennas at 22.7 GHz. (a) Original antenna; (b) parabola horn; (c) flat horn.

\subsection{The Impact of the $3 D$ Print Materials}

\subsubsection{The Nano Copper Wire (NCW) Based Conductors}

Regardless of the matching that occurs between the antenna and the open space, loss in the material contributes to antenna gain degradation $[25,26]$. The average power $P_{t(a v g)}$ dissipated in the conductor, as shown in (1), indicates a strong dependence on the conductivity $\sigma$, where $T$ is the transmission coefficient, $\alpha$ is the attenuation constant, and $E_{0}$ is the amplitude. Thus, as the proposed horns are fabricated by a relatively lossy material filled with NCW, the impact of the filler's conductivity on radiation efficiency must be accounted for.

$$
P_{t(a v g)}=\frac{1}{2} \sigma\left|E_{0}\right|^{2}|T|^{2} \int_{z=0}^{\infty} e^{-2 \alpha z} \mathrm{dz}=\frac{\sigma\left|E_{0}\right|^{2}|T|^{2}}{4 \alpha}
$$


The conductive NCW for the filament is chosen for the fabrication because, compared to the carbon black (CB) and carbon nanotubes (CNT), it provides a relatively higher conductivity. According to the manufacturer, the highest level of conductivity is around $1.6 \times 10^{4} \mathrm{~S} / \mathrm{m}$, but it drops with the variation of the raster angle orientation, the extrusion temperature, and the flow rate during the printing process.

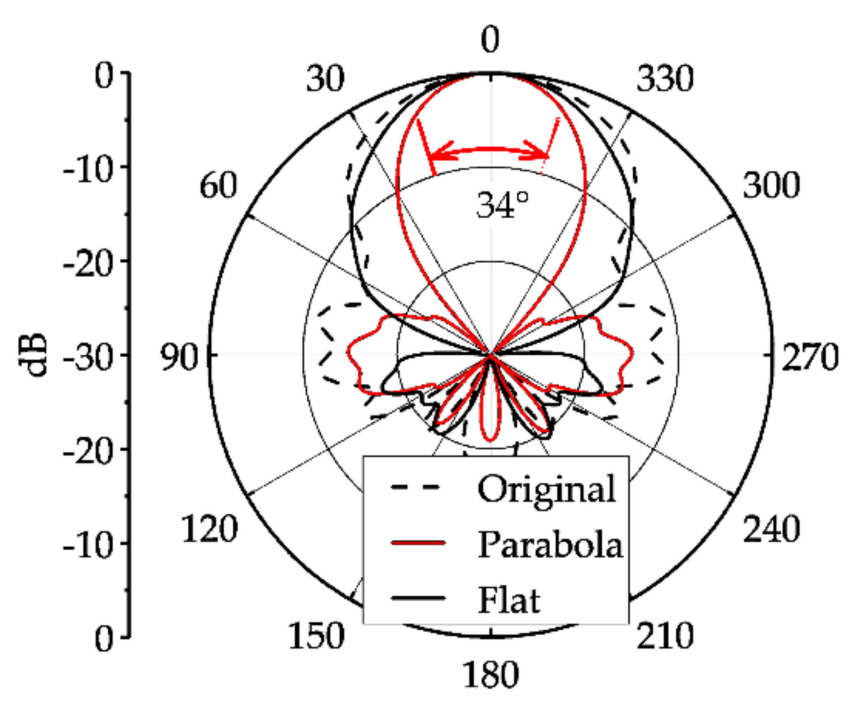

(a)

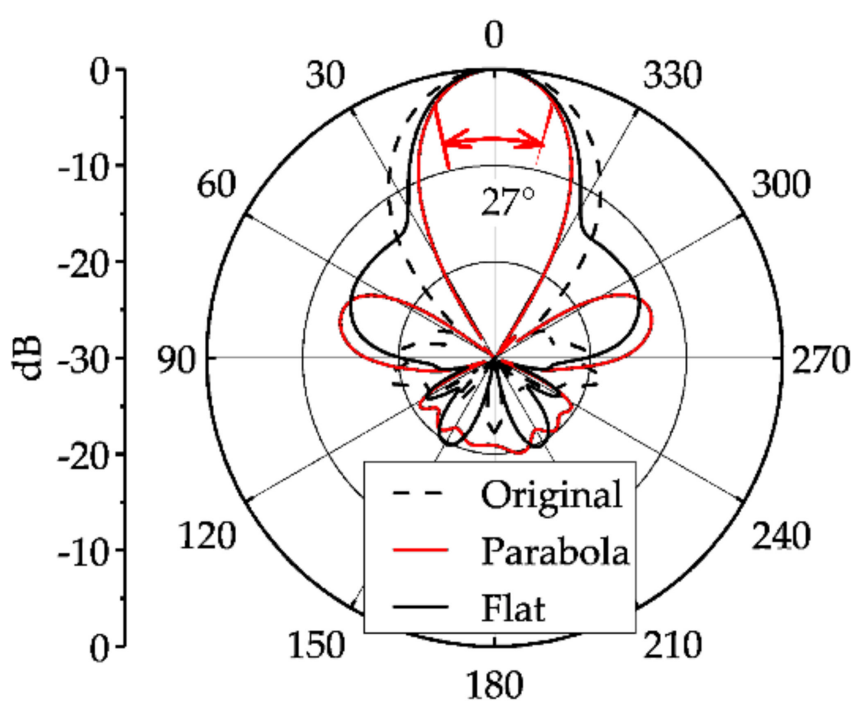

(b)

Figure 4. Simulated radiation patterns of three investigated antennas at 22.7 GHz. (a) E-plane; (b) H-plane.

The simulated radiation characteristics vs. the conductivity $\sigma$ of the NCW from 0 to $1.6 \times 10^{4} \mathrm{~S} / \mathrm{m}$ is shown in Figure 5. In the simulation, copper $\left(5.96 \times 10^{7} \mathrm{~S} / \mathrm{m}\right)$ is set as a reference material. Furthermore, the simulated radiation efficiency of the original antenna (Figure 3a) is added, indicating the impact of the loss, when using NCW, on the radiation efficiency. A supporting structure (see Figure 2) following the horn shape constructed from PLA is also considered in the simulation. It can be seen that, for the conductivity in a relatively worse case, from $1 \times 10^{3}$ to $7 \times 10^{3} \mathrm{~S} / \mathrm{m}$, the power loss in the NCW structure leads to a reduction in radiation efficiency, from around $11.4 \%$ to $2.4 \%$, compared with the copper.

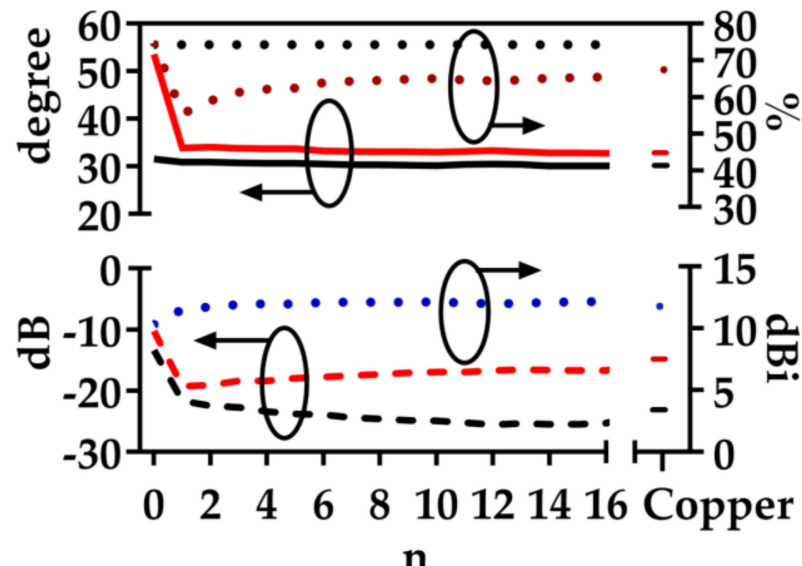

n
- E-plane HPBW

- - E-plane SLL

- H-plane HPBW

- - H-plane SLL

- Radiation efficiency

- Realized gain

- Radiation efficiency(Original)

\section{Conductivity $\left(\sigma=\mathbf{n} \times 10^{3}\right.$ siemens $\left./ \mathrm{m}\right)$}

Figure 5. The impacts on the radiation characteristics of the conductivity of the NCW horn. 
The most significant finding from the results is that when the NCW conductivity is below the ideal case (from $7 \times 10^{3}$ to $1.6 \times 10^{4} \mathrm{~S} / \mathrm{m}$ ), the proposed horn enables satisfactory radiation performance cf. the copper. For example, when $\sigma=7 \times 10^{3} \mathrm{~S} / \mathrm{m}$, the HPBW in the E-plane only has a $0.06^{\circ}$ increase, while the corresponding SLL has a $3.05 \mathrm{~dB}$ reduction, which sustains a wide-realized gain of around $12.14 \mathrm{dBi}$. Even for the worst cases of conductivity, for example at $1 \times 10^{3} \mathrm{~S} / \mathrm{m}$, the HPBWs in both the E- and the H-plane only have a $0.8^{\circ}$ and $0.2^{\circ}$ increase compared to the copper, which only has a $0.3 \mathrm{dBi}$ decrease in the realized gain. These findings show that the proposed approach offers an easy option for improving SIW H-plane performance due to its low-cost fabrication and a high availability of the material.

The influences of surface roughness of the finished structure using FDM include extrusion temperature, print speed, wall thickness, and print orientation. A recent 3D print reflector antenna presented in [27] demonstrates that such a roughness influences the total loss at less than $0.1 \mathrm{~dB}$ at $\mathrm{THz}$ frequencies. Therefore, with regard to the frequency in our work, the total loss caused by the roughness is expected to be very low. This loss could be further reduced by using a smooth surface technique [28].

\subsubsection{The Polylactic Acid (PLA) Dielectric}

A parameter study of the PLA supporting material is also conducted to determine its impact on radiation. This is because the measured dielectric constant $\varepsilon_{r}$ and the loss tangent of PLA vary at different frequencies. Generally, the measurement results in [25] and [26] report that the dielectric constant of the PLA drops from 3.5 to 2.7 as the frequency increases from 9 to $40 \mathrm{GHz}$. Given our printing accuracy, to control and minimize the power loss in the supporting structure, we perform the simulation for the dielectric constant $\varepsilon_{r}$ of the support, shown in Figure 6a. Furthermore, according to the measurement in [25] and [26], as the loss tangent of the PLA has a small shift $\left( \pm 0.2 \times 10^{-3}\right)$ when given a wide frequency range from 9 to $40 \mathrm{GHz}$, we fix the loss tangent to 0.014 , and a simulation result for $\varepsilon_{r}=3.4$ and $\tan \delta=0$ is considered as a reference. From the results, compared with the reference, the maximum difference of radiation efficiency and realized gain are shown to be around $4 \%$ and $0.6 \mathrm{dBi}$. Regarding the normalized radiation characteristics, as the dielectric constant increases, the narrow E- and H-plane HPWBs are maintained at around $34^{\circ}$ and $31^{\circ}$, with the corresponding SLLs at around $-19 \mathrm{~dB}$ and $-23 \mathrm{~dB}$, respectively. The impact of the thickness $L_{g}$ of the supporting structure on radiation performance is investigated at $22.7 \mathrm{GHz}$ in Figure $6 \mathrm{~b}$, for $L_{g}$ ranging from $0.5 \mathrm{~mm}$ to $1 \mathrm{~mm}$. The case in which the NCW horn is directly contacting the metal plate of the substrate $\left(L_{g}=0 \mathrm{~mm}\right)$ is considered as a reference. When compared to this reference, the maximum difference in the radiation efficiency is found to be about $2.4 \%$ for lengths $L_{g} \geq 0.5 \mathrm{~mm}$. Regarding the radiation pattern and realized gain, the beam widths in both planes keep stable at around $32^{\circ}$ in E-plane and $31^{\circ}$ in $\mathrm{H}$-plane, leading to a flat gain of around $12 \mathrm{dBi}$. These results show that the thickness of the structure does not have a significant impact on the improvement of the radiation pattern that can be achieved. 


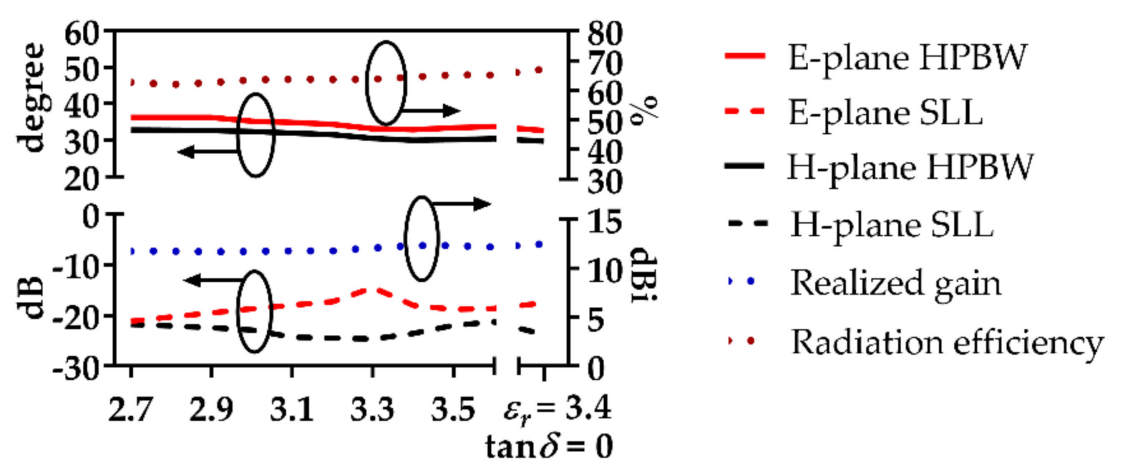

Dielectric constant $\varepsilon_{r}$ of the support

(a)

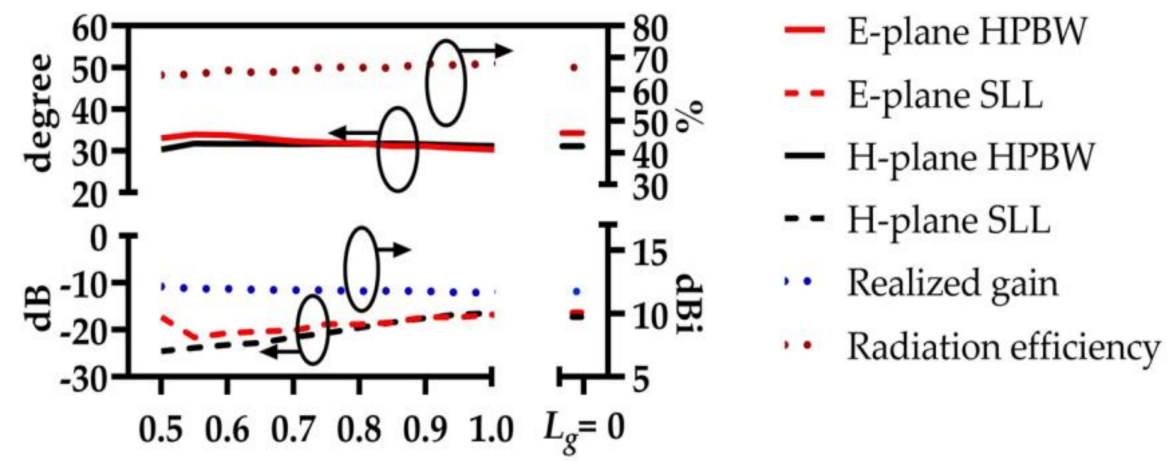

Supporting thickness $L_{g}(\mathrm{~mm})$

(b)

Figure 6. The study of the supporting material PLA on antenna performance. (a) The impact of the supports' dielectric constant; (b) the impact of the supporting thickness $L_{g}$.

\section{Antenna Fabrication and Measurement}

The antenna structure with dimensions as given in Table 1 is fabricated using the consumer-grade 3D printer 'Ultimaker 3', shown in Figure 7a,b. As the bandwidth (BW) improvement is not the focus in this work, the entire antenna is fed directly by a coaxial connector (Huber + Suhner's PC 3.5-mm) with a transition pin (73-Z-0-0-168) recognized for its narrow BW.

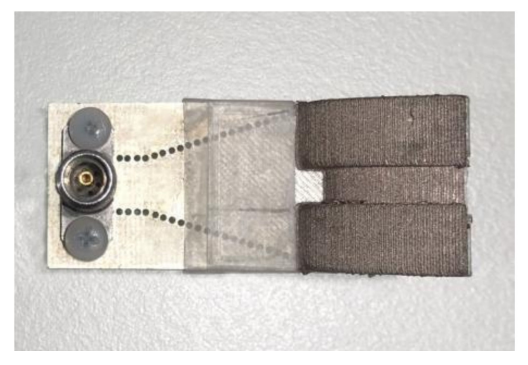

(a)

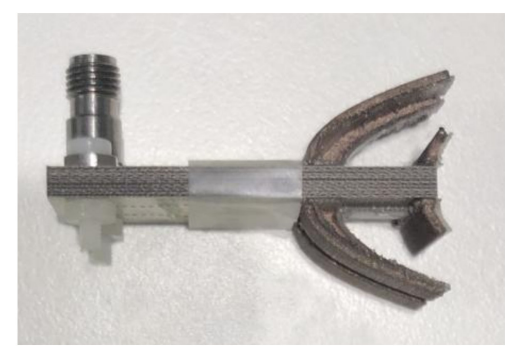

(b)

Figure 7. Fabricated prototype. (a) Top view; (b) side view.

\subsection{The Radiation Characteristics}

A good agreement between the simulated and measured radiation patterns of the proposed antenna, in normalized values, is shown in Figure 8a,b. Compared to the original antenna, the HPBW in the E-plane is narrowed by $17^{\circ}$. In terms of the SLL, a reduction by about $13 \mathrm{~dB}$ in the E-plane is reached, while there is only a $0.6 \mathrm{~dB}$ increase in the $\mathrm{H}$ - 
plane. An improvement of around $5.8 \mathrm{~dB}$ in the front-to-back ratio (FTBR) is also achieved. Compared to the simulation results, the H-plane has a $2.3^{\circ}$ wider HPBW and $2.6 \mathrm{~dB}$ higher SLL due to the imperfect finishing structure, and a shape change of the main lobe of around $30^{\circ} \leq \theta \leq 90^{\circ}\left(270^{\circ} \leq \theta \leq 330^{\circ}\right)$. This difference could be attributed to a possible uncertainty in the printing accuracy, the extrusion temperature, or the fabricated speed, leading to insufficient mobility and an uneven volume of the extruded wire. Further, FDM $3 \mathrm{D}$ printing also inherently introduces rough surfaces, leading to the path difference of the waves, and the phase error.

The antenna prototype is measured at multiple frequencies from 20 to $25 \mathrm{GHz}$. Figure 9 shows that in this frequency range, the proposed antenna provides stable and narrow radiation patterns. More specifically, from 22 to $24 \mathrm{GHz}$, the E- and $\mathrm{H}$-plane beamwidths continue reducing while the low E-plane SLLs below $-20 \mathrm{~dB}$ are maintained. The FTBR increases above $25 \mathrm{~dB}$ at around $23 \mathrm{GHz}$ as a result of the wavelength variation. The simulated radiation efficiency, covering the measured frequency band, is plotted as a reference. At the designed frequency of $22.7 \mathrm{GHz}$, the radiation efficiency is around $68 \%$. The measurement results indicate that to improve the radiation performance of the SIW Hplane horn antenna at multiple frequencies, the proposed antenna offers an easy fabrication solution cf. the high cost and precision techniques of the PCB manufacturing.

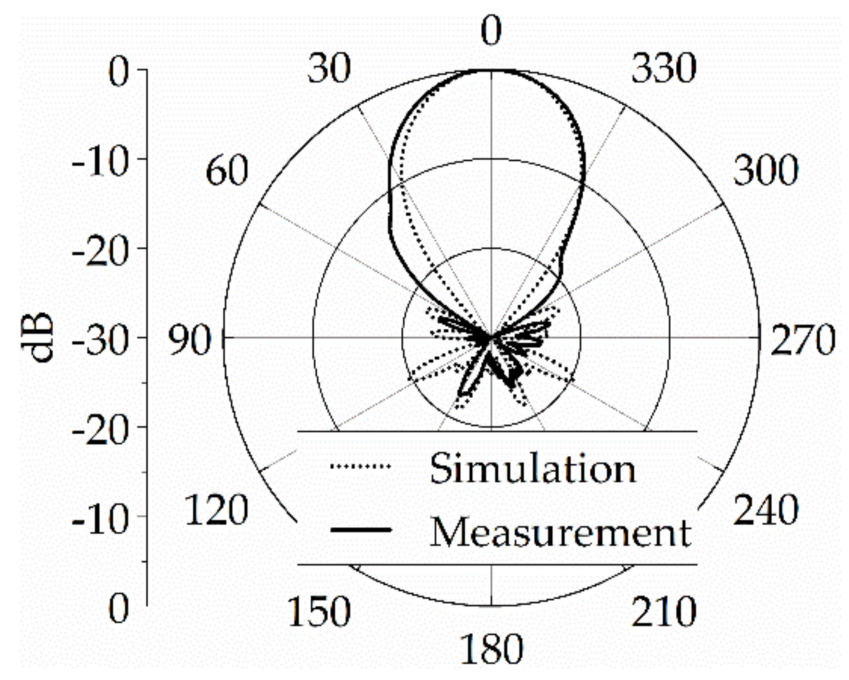

(a)

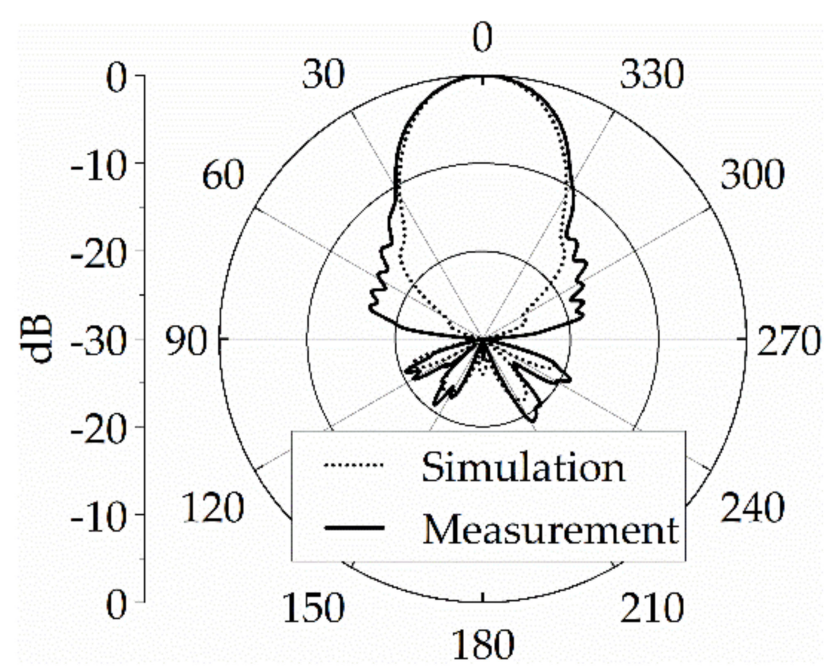

(b)

Figure 8. Measured and simulated pattern at 22.7 GHz; (a) E-plane; (b) H-plane.

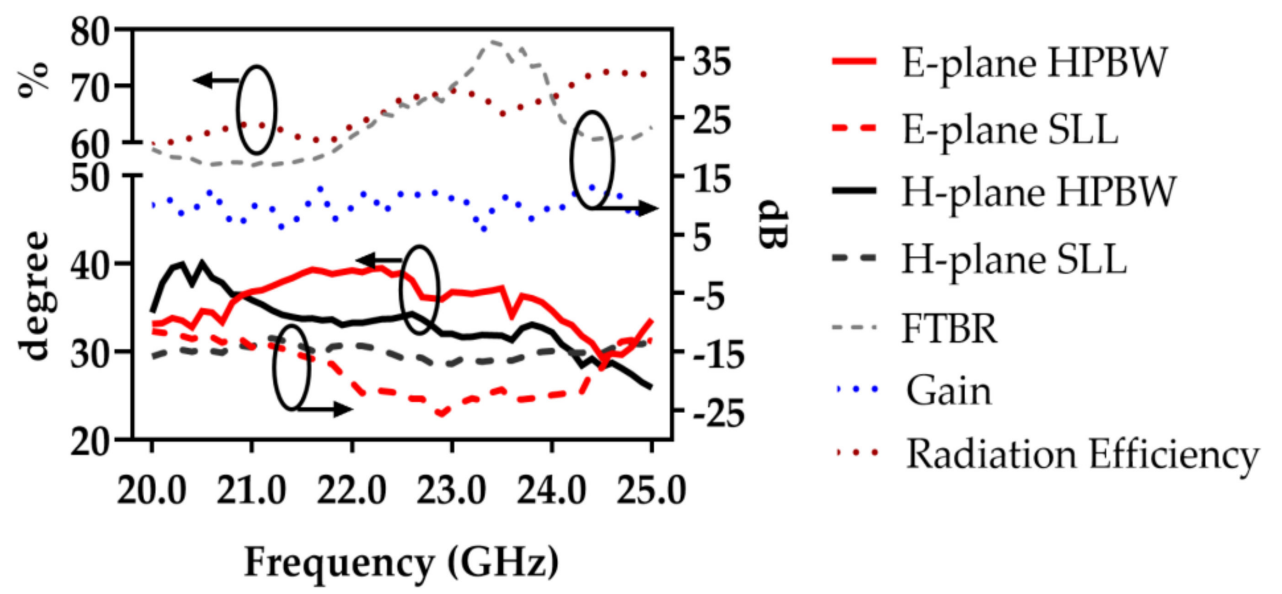

Figure 9. The measured radiation characteristics from 20 to $25 \mathrm{GHz}$. 


\subsection{The Reflection Coefficient $\left|S_{11}\right|$}

The reflection coefficient $\left|S_{11}\right|$ of the proposed antenna, shown in Figure 10, is measured with an E8364C PNA network analyzer. The measurement results agree well with the simulation for the proposed antenna, which is directly fed by the coaxial connector (50 $\Omega$ port impedance) with a transition pin. A relative impedance BW of about $5.3 \%$ ( 21.8 to $23.0 \mathrm{GHz}$ ) for $\left|\mathrm{S}_{11}\right| \leq-10 \mathrm{~dB}$ is measured. To show that the narrow $\mathrm{BW}$ is mainly due to the feeding technique, the proposed antenna, fed by a waveguide (wave port excitation with $\mathrm{TE}_{10}$ mode in the HFSS) with a pair of tuning vias, is simulated, as shown in Figure 10. Through the use of waveguide feeding into the same panel, a relative impedance BW of about $15.3 \%$ (22.1 to $25.6 \mathrm{GHz}$ ) for $\left|\mathrm{S}_{11}\right| \leq-10 \mathrm{~dB}$ can be achieved.

In this section, the results of the radiation characteristics, and the matching, provide further support for the excellent performance of the proposed antenna in maintaining the stable radiation within the wideband.

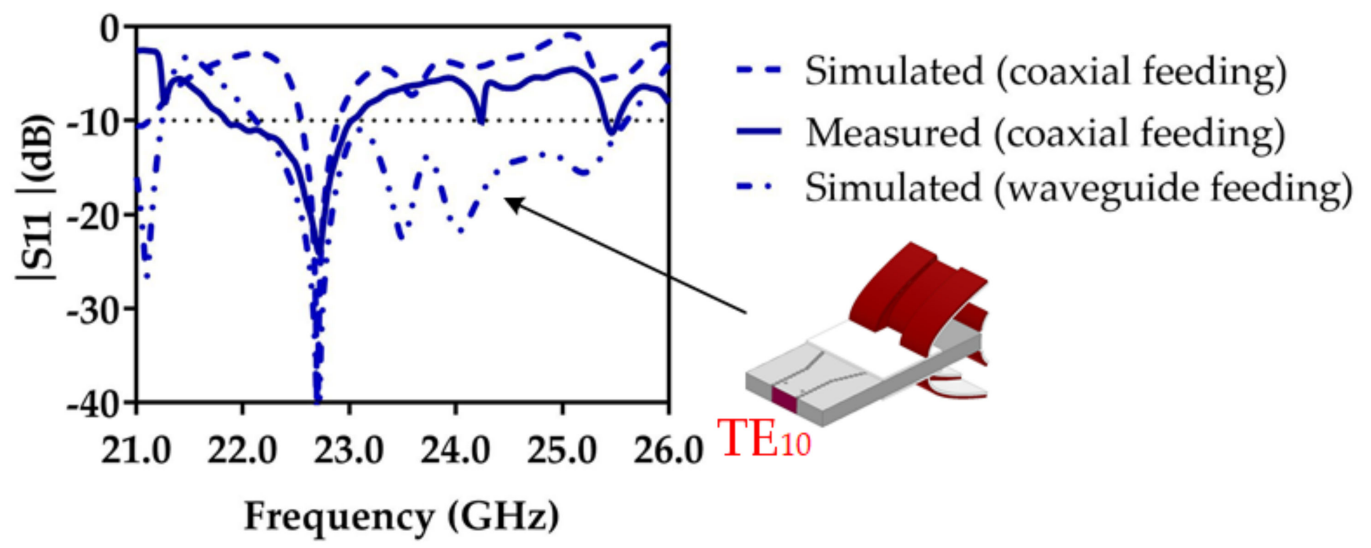

Figure 10. The reflection coefficient $\left|S_{11}\right|$ of the proposed antenna using different feedings.

\section{Discussion}

A summary of recent SIW H-plane horn antenna designs is shown in Table 2. All results are selected based on the measurement results of a single antenna element on one single PCB layer with the best radiation performance extracted for the wideband designs. In terms of the feeding technique and bandwidth, $[11-13,24]$ show that such a class of antennas provides narrow bandwidth when a 90-degree coaxial to SIW transition is used. On the contrary, the waveguide transition implemented in $[29,30]$ shows a wider bandwidth. 
Table 2. Summary of recent works.

\begin{tabular}{|c|c|c|c|c|c|c|c|c|c|c|c|}
\hline Parameters & [10] & [11] & [13] & [14] & [24] & [29] & [30] & [31] & [32] & \multicolumn{2}{|c|}{ This Work } \\
\hline Frequency (GHz) & 27 & 22.7 & 20.5 & 14.8 & 12.3 & 26.7 & 40 & 35.5 & 24 & \multicolumn{2}{|c|}{22.7} \\
\hline Gain $(\mathrm{dBi})$ & 8.83 & 10.9 & 14 & 7.1 & 10.4 & 9 & 15.4 & 7.87 & 8 & \multicolumn{2}{|c|}{12} \\
\hline FTBR (dB) & 27 & 22 & 24 & 15 & $21.6 *$ & $22 *$ & N. A & $15^{*}$ & 20 * & \multicolumn{2}{|c|}{27.8} \\
\hline HPBW $\left(^{\circ}\right) \quad E$ & 80 & 52 & 44 & $160 *$ & $140 *$ & $35 *$ & 29.1 & 29.1 & $40^{*}$ & \multicolumn{2}{|c|}{35} \\
\hline HPBW ( $\left.{ }^{\circ}\right)$ & 60 & 30 & 32 & 45 & 40 & 29.6 & 19.5 & 19.5 & $28^{*}$ & \multicolumn{2}{|c|}{33.2} \\
\hline SLL (dB) & $-10^{*}$ & $-10 *$ & $-10 *$ & N. A & $-5^{*}$ & $-4^{*}$ & $-8^{*}$ & $-8^{*}$ & $-4 *$ & \\
\hline SLL (dB) & $-11 *$ & -15.6 & -20 & -20 & -13 & -9.53 & $-15^{*}$ & $-15^{*}$ & $-10 *$ & \multirow{2}{*}{\multicolumn{2}{|c|}{-15}} \\
\hline$\varepsilon_{\mathrm{r}}$ of $\mathrm{PCB}$ & 4.8 & 5.1 & 2.2 & 3.27 & 6.15 & 4.4 & 2.2 & 3.0 & 4.8 & & \\
\hline Technique on feeding & Coaxial pin & Coaxial pin & Coaxial pin & $\begin{array}{l}\text { Reflector, } \\
\text { coaxial pin }\end{array}$ & Coaxial pin & Waveguide & Waveguide & Microstrip line & Waveguide & Coaxial pin & Waveguide \\
\hline BW (\%) & $2.6^{*}$ & & 5 & $16^{1}$ & & 34 & $\mathrm{~K}$ and $\mathrm{Ka}$ & $7.6^{*}$ & $40 *$ & 5.3 & 15.3 \\
\hline
\end{tabular}

The value followed by ${ }^{\prime * \prime}$ indicates that the specific measurement result is not mentioned in the text. It is the approximation of the figures provided by authors. 
Regarding the radiation pattern and gain enhancement, it can be concluded that for SIW H-plane horn antennas, there are many ways to improve H-plane performance as plane modification is easy to realize using the traditional PCB fabrication process. The work presented in [14,24] reveals that the gain enhancement is limited by the wide E-plane pattern. Although the designs in $[13,32]$ attempt to improve E-plane performance, they require either a high-precision technique or a complex design process, and the radiation patterns are unstable at multiple frequencies. Compared with the predesigned SIW H-plane horn antenna [11], the proposed NCW horn offers an enhanced gain of about $1.1 \mathrm{~dB}$ and an increased BW of around 3.3\%. It is worth emphasizing that the parasitic E-plane horn maintains a good $\mathrm{H}$-plane performance while substantially narrowing the E-plane pattern by about $17^{\circ}$ of the HPBW and lowering the SLL by about $-13 \mathrm{~dB}$. A further improvement in these radiation characteristics is expected to be achieved by utilizing a more conductive $3 \mathrm{D}$ printing material.

Due to these reasons, to extend the use of SIW H-plane horn antennas, our proposed structure combined with 3D printed horns offers a better solution for the benefits of superior radiation performance and design simplicity.

\section{Conclusions}

In this paper, we concentrate our attention on gain enhancement by narrowing the E-plane pattern of the SIW H-plane horn antenna with a simple design. To achieve this, a 3D printed parabola horn is attached to a pre-designed antenna. Based on the analysis and simulations, the optimized structures are fabricated by consumer-grade multi-material FDM printing, using conductive material NCW composite and PLA. According to the measurement results, at the designed frequency, it offers a gain of $12 \mathrm{dBi}$ with an E-plane $\mathrm{HPBW}$ at $35^{\circ}$ and SLL at $-23 \mathrm{~dB}$, which prove to be $17^{\circ}$ narrower and $13 \mathrm{~dB}$ lower than the pre-designed antenna. The experimental work and findings presented here provide a significant contribution to research on their low-cost fabrication and easy design, together with the achievement of a superior radiation performance.

Author Contributions: Conceptualization, S.H. and K.Y.C.; investigation, S.H. and Y.W.; writingoriginal draft preparation, Y.W. and S.H.; writing-review and editing, K.Y.C. and R.R.; supervision, R.R. All authors have read and agreed to the published version of the manuscript.

Funding: This research received no external funding.

Data Availability Statement: The data presented in this study are available on request from the first author.

Acknowledgments: The authors would like to thank Ken Smart from CSIRO for strongly supporting the antenna measurements.

Conflicts of Interest: The authors declare no conflict of interest.

\section{References}

1. Bozzi, M.; Georgiadis, A.; Wu, K. Review of substrate-integrated waveguide circuits and antennas. IET Microw. Antennas Propag. 2011, 5, 909-920. [CrossRef]

2. Althuwayb, A.A. MTM- and SIW-Inspired Bowtie Antenna Loaded with AMC for 5G mm-Wave Applications. Int. J. Antennas Propag. 2021, 2021, 6658819. [CrossRef]

3. Yang, Y.; Cai, Y.; Chan, K.Y.; Ramer, R.; Guo, Y.J. MEMS-loaded millimeter wave frequency reconfigurable quasi-Yagi dipole antenna. Asia-Pac. Microw. Conf. Proc. APMC 2011, 1318-1321, 6174002.

4. Chan, K.Y.; Daneshmand, M.; Mansour, R.R.; Ramer, R. Novel beam design for compact RF MEMS series switches. Asia-Pac. Microw. Conf. Proc. APMC 2007, 1257, 4554572.

5. Afzal, M.U.; Matekovits, L.; Esselle, K.P.; Lalbakhsh, A. Beam-Scanning Antenna Based on Near-Electric Field Phase Transformation and Refraction of Electromagnetic Wave Through Dielectric Structures. IEEE Access 2020, 8, 199242-199253. [CrossRef]

6. Althuwayb, A.A. Enhanced radiation gain and efficiency of a metamaterial inspired wideband microstrip antenna using substrate integrated waveguide technology for sub-6 GHz wireless communication systems. Microw. Opt. Technol. Lett. 2021, 63, 1892-1898. [CrossRef] 
7. Dong, Y.; Itoh, T. Miniaturized substrate integrated waveguide slot antennas based on negative order resonance. IEEE Trans. Antennas Propag. 2010, 58, 3856-3864. [CrossRef]

8. $\mathrm{Gu}, \mathrm{Z}$; $\mathrm{Wu}$, X.H.; Zhang, Q. Substrate-integrated E-plane waveguide horn antenna and antenna array. IEEE Trans. Antennas Propag. 2018, 66, 2382-2391. [CrossRef]

9. Bayat-Makou, N.; Kishk, A.A. Substrate integrated horn antenna with uniform aperture distribution. IEEE Trans. Antennas Propag. 2017, 65, 514-520. [CrossRef]

10. Wang, H.; Fang, D.G.; Zhang, B.; Che, W.Q. Dielectric loaded substrate integrated waveguide (SIW) H-plane horn antennas. IEEE Trans. Antennas Propag. 2010, 58, 640-647. [CrossRef]

11. Gong, L.; Chan, K.Y.; Ramer, R. Substrate Integrated Waveguide H-Plane Horn Antenna with Improved Front-to-Back Ratio and Reduced Sidelobe Level. IEEE Antennas Wireless Propag. Lett. 2016, 15, 1835-1938. [CrossRef]

12. Iigusa, K.; Li, K.; Sato, K.; Harada, H. Gain Enhancement of H-Plane Sectoral Post-Wall Horn Antenna by Connecting Tapered Slots for Millimeter-Wave Communication. IEEE Trans. Antennas Propag. 2012, 60, 5548-5556. [CrossRef]

13. Jamshidi-Zarmehri, H.; Neshati, M.H. Design and Development of High-Gain SIW H-Plane Horn Antenna Loaded With Waveguide, Dipole Array, and Reflector Nails Using Thin Substrate. IEEE Trans. Antennas Propag. 2019, 67, 2813-2818. [CrossRef]

14. Esquius-Morote, M.; Fuchs, B.; Zurcher, J.; Mosig, J.R. Novel thin and compact H-plane SIW horn antenna. IEEE Trans. Antennas Propag. 2013, 61, 2911-2920. [CrossRef]

15. Huang, S.; Chan, K.Y.; Fu, Y.; Ramer, R. Dielectric-loaded substrate integrated waveguide H-plane horn antenna with embedded air cavity. IET Microw. Antennas Propag. 2021, 15, 154-162. [CrossRef]

16. Huang, S.; Chan, K.Y.; Ramer, R. Dielectric-Loaded SIW H-Plane Horn Antenna With Gradient Air Slots. IEEE Antennas Wirel. Propag. Lett. 2020, 20, 43-47. [CrossRef]

17. Chan, K.Y.; Ramer, R.; Sorrentino, R. Low-Cost Ku-Band Waveguide Devices Using 3-D Printing and Liquid Metal Filling. IEEE Trans. Microw. Theory Tech. 2018, 66, 3993-4001. [CrossRef]

18. Bi, Y.; Li, Y.; Wang, J. 3D-Printed Wideband Cassegrain Antenna with a Concave Sub-Reflector for 5G Millimeter-Wave TwoDimensional Multibeam Applications. IEEE Trans. Antennas Propag. 2020, 68, 4362-4371. [CrossRef]

19. Li, Y.; Lei, G.; Wang, J.; Da, S.; Cao, D.; Wang, J.; Liu, Y. 3-D printed high-gain wideband waveguide fed horn antenna arrays for millimeter-wave applications. IEEE Trans. Antennas Propag. 2019, 67, 2868-2877. [CrossRef]

20. Wang, K.X.; Wong, H. A wideband millimeter-wave circularly polarized antenna with 3-D printed polarizer. IEEE Trans. Antennas Propag. 2017, 65, 1038-1046. [CrossRef]

21. Kordiboroujeni, Z.; Bornemann, J. Designing the width of substrate integrated waveguide structures. IEEE Microw. Wirel. Compon. Lett. 2013, 23, 518-520. [CrossRef]

22. $\mathrm{Xu}, \mathrm{F} . ; \mathrm{Wu}, \mathrm{K}$. Guided-wave and leakage characteristics of substrate integrated waveguide. IEEE Trans. Microw. Theory Techn. 2005, 53, 66-73.

23. Balanis, C.A. Antenna Theory: Analysis and Design, 4th ed.; John Wiley \& Sons: Hoboken, NJ, USA, 2016; ISBN 978-1118642061.

24. Luo, Y.; Bornemann, J. Substrate integrated waveguide horn antenna on thin substrate with back-lobe suppression and its application to arrays. IEEE Antennas Wireless Propag. Lett. 2017, 16, 2622-2625. [CrossRef]

25. Felício, J.M.; Fernandes, C.A.; Costa, J.R. Complex permittivity and anisotropy measurement of 3D-printed PLA at microwaves and millimeter-waves. In Proceedings of the 22nd International Conference on Applied Electromagnetics and Communications (ICECOM), Dubrovnik, Croatia, 15 September 2016.

26. Huber, E.; Mirzaee, M.; Bjorgaard, J.; Hoyackm, M.; Noghanian, S.; Chang, I. Dielectric property measurement of PLA. In Proceedings of the IEEE International Conference on Electro Information Technology (EIT), Grand Forks, ND, USA, 7 May 2016.

27. Adibelli, S.; Juyal, P.; Zajic, A. On the Surface Roughness and Smoothing in the 3D Printed THz Reflectors. IEEE Int. Symp. Antennas Propag. USNC-URSI Radio Sci. Meet. 2019, 15, 593-594.

28. Sung-Uk, Z.; Jonghyeuk, H.; Hyun-Wook, K.; Byoung-Chul, S. Thermo-mechanical properties of ABS parts fabricated by fused deposition modeling and vapor smoothing. Int. Conf. Therm. Mech. Multi-Phys. Simul. Exp. Microelectron. Microsyst. 2017, 6, 7926222.

29. Cai, Y.; Qian, Z.; Zhang, Y.S.; Cao, W.Q. A compact wideband SIW-fed dielectric antenna with end-fire radiation pattern. IEEE Trans. Antennas Propag. 2016, 64, 1502-1507. [CrossRef]

30. Park, W.B.; Lee, J.M.; Lee, S.; Park, Y.M.; Hwang, K.C. A 18-40 GHz Substrate Integrated Waveguide H-Plane Horn Antenna. IEEE Trans. Antennas Propag. 2018, 66, 6322-6327. [CrossRef]

31. Wang, L.; Yin, X.X.; Li, S.L.; Zhao, H.X.; Liu, L.L.; Zhang, M. Phase corrected substrate integrated waveguide h-plane horn antenna with embedded metal-via arrays. IEEE Trans. Antennas Propag. 2014, 62, 1854-1861. [CrossRef]

32. Cai, Y.; Qian, Z.P.; Zhang, Y.S.; Jin, J.; Cao, W.Q. Bandwidth enhancement of SIW horn antenna loaded with air-via perforated dielectric slab. IEEE Antennas Wirel. Propag. Lett. 2014, 13, 571-574. 